\title{
ANÁLISE BIBLIOMÉTRICA DOS ARTIGOS CIENTÍFICOS EM FINANÇAS PUBLICADOS NA REVISTA DE ADMINISTRAÇÃO DE EMPRESAS (RAE) DA FGV/SP, NO PERÍODO DE 2006 A 2016
}

BIBLIOMETRIC ANALYSIS OF SCIENTIFIC ARTICLES IN FINANCE PUBLISHED IN FGV/SP'S THE REVISTA DE ADMINISTRAÇÃO DE EMPRESAS (RAE) FROM 2006 TO 2016

Recebido em: 02/06/2017 • Aprovado em: 09/08/2017 Avaliado pelo sistema double blind review Editora Científica: Claudia Stadtlober DOI 10.13058/raep.2017.v18n3.631

\section{ROGÉRIO MARTINS FURTADO DESOUZA rogerio.furtado@unimontes.br MATHEUS WIVER MOTA BAIA}

ISABELA CRISTINA MENDES COSTA

RICARDO SENAMACHADO

ANA LUIZA BARBOSA MENDES

MATEUS VIEIRA SOUTO

UNIVERSIDADE ESTADUAL DE MONTES CLAROS

\begin{abstract}
RESUMO
O presente artigo teve como objetivo apresentar os resultados de um estudo que buscou identificar o perfil dos artigos científicos em finanças publicados na Revista de Administração de Empresas (RAE) da Fundação Getulio Vargas de São Paulo (FGV/SP), no período de 2006 a 2016, com vistas a ampliar o conhecimento acerca da evolução da divulgação dos estudos científicos brasileiros na área. Para a realização deste artigo, foi executada uma pesquisa descritiva; quanto ao procedimento, foi de tipo bibliográfico e bibliométrico. A abordagem foi quantitativa. Para a organização e tabulação dos dados foi utilizado o software MS-Excel. Os resultados permitiram observar que a maioria dos artigos de finanças publicados pela RAE, durante o período analisado, foi produzida por profissionais brasileiros com doutorado, do gênero masculino, vinculados a instituições estabelecidas na região Sudeste, principalmente, a FGV e a USP. Observou-se, também, que houve uma grande variedade entre os temas de finanças abordados, com a predominância por temas voltados ao mercado financeiro e à gestão de grandes negócios, sendo que estudos sobre governança corporativa e mercado de capitais foram os mais publicados.

Palavras-Chave: Administração. Finanças. Artigos Científicos. Bibliometria. RAE.
\end{abstract}

\section{ABSTRACT}

This article aims to present the results of a study that sought to identify the profile of the scientific articles in finance published in the Revista de Administração de Empresas (RAE) of the Fundação Getulio Vargas de São Paulo (FGV/ SP), from 2006 to 2016, in order to contribute to the existing knowledge about the evolution of the dissemination of Brazilian scientific studies in this field. To this end, a descriptive research was performed, adopting a bibliographic and bibliometric procedure with a quantitative approach. For the organization and tabulation of the data, the MS-Excel software was used. The results showed that most of the financial articles published by RAE during the analyzed period were produced by Brazilian professionals with a doctoral degree, male, belonging to institutions in the Brazilian Southeast region, mainly FGV and USP. It was also observed that there was a great variety among the financial topics addressed, with the predominance of subjects related to the financial market and the management of big business. Corporate Governance and Capital Markets were the most published.

Keywords: Management. Finance. Scientific articles. Bibliometrics. RAE. 
Finanças é uma área do conhecimento profundamente importante tanto para as organizações quanto para os indivíduos e a sociedade em geral, pois a boa gestão dos seus recursos financeiros é essencial para a sobrevivência de todos em meio à complexidade de um mundo cada vez mais globalizado.

Gitman (2010, p. 3) conceitua finanças como sendo "a arte e a ciência de administrar o dinheiro". Para ele, como todos estão envolvidos com finanças, compreender suas especificidades é profundamente necessário para equacionar as necessidades de fundos e obter um melhor aproveitamento das oportunidades de investimentos, dessa maneira, proporcionando melhores decisões financeiras.-

Por consequência do reconhecimento da importância de tais aspectos, a produção científica em finanças, no Brasil, sempre, foi muito volumosa. Várias foram as contribuições dadas à ciência por meio da publicação de artigos, teses, dissertações e livros. Além disso, houve considerável espaço de divulgação nas publicações acadêmicas especializadas das áreas de administração, contabilidade e economia, de modo a acompanhar as inovações surgidas no cenário internacional e a adequação destas à realidade nacional.

Conforme explica Assaf Neto (2014), o estudo de finanças é dinâmico e ajusta-se continuamente aos diversos momentos e às transformações da economia, entende-se que tal dinâmica tende a, também, influenciar na escolha dos textos a serem apresentados nas publicações científicas. Neste aspecto, perceber como tal situação processa-se ao longo do tempo e quais suas especificidades, torna-se relevante para compreender a evolução da discussão dos diversos temas de finanças.

Um dos meios mais adequados para se mensurar e analisar a evolução da produção científica em determinada área é o estudo bibliométrico. Segundo Macias-Chapula (1998, p. 1), "a Bibliometria é o estudo dos aspectos quantitativos da produção, disseminação e uso da informação registrada". Guedes (2012, p. 3) explica que a bibliometria "é constituída por um conjunto de leis e princípios empíricos, que contribuem para o estabele- 
cimento da fundamentação teórica da Ciência da Informação", portanto, conhecida como um método eficaz para a medição do que foi divulgado sobre determinado tema, assunto, área do conhecimento ou mesmo do todo veiculado por um ou mais veículos de comunicação no decurso do tempo.

Neste cenário, observa-se que uma das revistas que mais se destaca na área de administração é a Revista de Administração de Empresas da Fundação Getulio Vargas de São Paulo (RAE) - FGV/SP, como um dos periódicos acadêmico-científicos de administração mais tradicionais e conceituados do Brasil. A RAE tem o conceito Qualis A2 da CAPES/MEC e, segundo o publicado em seu site (RAE, 2017), está entre as 10 revistas brasileiras no ranking de impacto medido pelo Journal Citation Reports (JCR) e aparece também em $18^{\circ}$ lugar no ranking do Google Acadêmico com as principais publicações em língua portuguesa, abrangendo todas as áreas da ciência.

Com a compreensão de tais aspectos, partindo do questionamento de qual seria o perfil dos artigos científicos em finanças publicados na Revista de Administração de Empresas (RAE) da Fundação Getulio Vargas de São Paulo (FGV/SP), no período de 2006 a 2016, este trabalho objetivou identificar as características dos artigos científicos em finanças e o perfil dos seus autores, publicados na RAE, em tal período, utilizando-se de uma análise bibliométrica com vistas a ampliar o conhecimento acerca da evolução da divulgação dos estudos científicos brasileiros na área.-

Para auxiliar na realização do objetivo principal, foram delineados os seguintes objetivos específicos: identificar a evolução anual do número de artigos publicados em finanças e sua participação frente ao total de artigos publicados; individuar o perfil dos autores quanto ao gênero, à titulação e instituição de origem; discriminar o número de artigos publicados em finanças por subárea do conhecimento. 


\section{REFERENCIAL TEÓRICO}

Para Gitman (2010, p. 3), finanças é uma área do conhecimento que abrange todos os processos, instituições, instrumentos e mercados "envolvidos na transferência de dinheiro entre pessoas, empresas e órgãos governamentais". E, nesse sentido, o corpo teórico de conhecimentos sobre finanças vem sofrendo mudanças no decurso dos anos para se adaptar às transformações da economia moderna, incorporando novos modelos, técnicas e formas de pensar em finanças e, continuamente, agregando novas abordagens e teorias sem, entretanto, abrir mão dos seus fundamentos básicos.

A administração financeira é a área da administração que agrega e utiliza os conhecimentos relacionados a finanças voltados à gestão dos recursos financeiros. Segundo Assaf Neto (2014, p. 12), a administração financeira volta-se, principalmente, para as seguintes funções:

- Planejamento financeiro, o qual procura evidenciar as necessidades de crescimento da empresa, assim como identificar eventuais dificuldades e desajustes futuros.

- Controle financeiro, que se dedica a acompanhar e avaliar todo o desempenho financeiro da empresa, como custos e despesas, margens de ganhos, volume de vendas, liquidez de caixa, endividamento, etc.

- Administração de ativos, que deve perseguir a melhor estrutura, em termos de risco e retorno, dos investimentos (ativos) empresariais, e proceder a um gerenciamento eficiente de seus valores.

- Administração de passivos, que se volta para a aquisição de fundos (financiamentos) e o gerenciamento de sua composição (proporção entre capital próprio e capital de terceiros), procurando definir a estrutura de capital mais adequada em termos de liquidez, redução de seus custos e risco financeiro.

Para o estudo e o aprimoramento de tais funções, os conteúdos a elas associados tendem a ser agrupados em grandes áreas conforme as suas características e aplicações. No Brasil, uma das principais entidades a realizar 
tal agrupamento é a Associação Nacional de Pós-graduação e Pesquisa em Administração (ANPAD), referência em administração no país, que adota uma organização das áreas da administração por temas, assim, propiciando melhor ordenamento dos trabalhos inscritos em seus encontros nacionais. A ANPAD (2017), dessa maneira, ordena os temas financeiros e os conteúdos a eles associados:

- Finanças Corporativas: abrange as decisões de financiamento, decisões de investimento, fusões e aquisições, política de dividendos e gestão de recursos de curto prazo.

- Governança Corporativa e Estrutura de Propriedade: envolve todos os estudos sobre os mecanismos de governança corporativa para redução de custos de agência.

- Gestão de Riscos e Derivativos: aborda os aspectos relacionados a riscos de mercado, de crédito e operacional, às estratégias de gestão de riscos e aos mercados de derivativos financeiros, de commodities e outros, tais como a termo, futuros, opções e swaps. Apreçamento de derivativos.

- Investimento e Apreçamento de Ativos: relaciona-se à avaliação de projetos de investimento, incluindo opções reais, e de investimentos em ativos individuais e carteiras. Envolve, também, o estudo de modelos de apreçamento de ativos (renda fixa e ações), a avaliação de desempenho de fundos e a avaliação de empresas.

- Mercados e Instituições Financeiras: aborda a gestão e avaliação de instituições financeiras e os aspectos regulatórios dos mercados, assim como a globalização financeira e integração de mercados.

- Finanças Comportamentais: abrange os estudos sobre o comportamento dos agentes, a tomada de decisão, a Teoria do Prospecto, heurísticas e vieses cognitivos, entre outras abordagens. Envolve, também, a análise da eficiência e anomalias dos mercados.

Uma das categorias que mais exerce influência sobre a organização das grandes áreas de finanças é a constituída pelos autores considerados 
ROGÉRIO MARTINS FURTADO DE SOUZA, MATHEUS WIVER MOTA ISSN 2358-09I7 BAIA, ISABELA CRISTINA MENDES COSTA, RICARDO SENA

MACHADO, ANA LUIZA BARBOSA MENDES \& MATEUS VIEIRA SOUTO

como clássicos, responsáveis por obras reconhecidas pela academia e que se caracterizam por abordar os principais temas e conteúdos financeiros. Observa-se que, conquanto não haja uma padronização obrigatória, há certa similaridade na organização de tais áreas por parte dos principais autores de finanças adotados no Brasil, tais como, Helfert (2000), Ross, Westerfield e Jaffe (2002), Gitman (2010) e Assaf Neto (2014).

Assaf Neto (2014) agrupa os conteúdos nas seguintes áreas: mercado financeiro, finanças corporativas e finanças pessoais. Já Gitman (2010) organiza-os em: decisões de investimento de longo prazo; decisões de financiamento de longo prazo; decisões financeiras de curto prazo e tópicos especiais de administração financeira. Ross, Westerfield e Jaffe (2002) organizam o conteúdo em: valor e orçamento de capital; estrutura de capital e política de dividendos; financiamento a longo prazo; planejamento financeiro e tópicos especiais em finanças. Por fim, Helfert (2000) adota uma organização mais simples, agrupando os conteúdos em apenas três áreas: decisões de investimento, decisões operacionais e decisões de financiamento.

Segundo esses autores, a área mercado financeiro objetiva estudar os comportamentos dos mercados, seus vários títulos e valores mobiliários negociados e as instituições financeiras que atuam nesse segmento; finanças corporativas focaliza seu estudo nos processos e nas tomadas de decisões nas organizações; e finanças pessoais estuda a gestão dos recursos financeiros por parte das pessoas físicas, seus investimentos e financiamentos.

A área investimentos de longo prazo aborda os fluxos de caixa para orçamento de capital e as técnicas de orçamento de capital, risco e retorno. A área financiamento de longo prazo trata das decisões de uso de capital de terceiros a longo prazo, abordando conteúdos como ações, opções, warrants, títulos conversíveis, arrendamento e derivativos, aborda também o custo de capital, a alavancagem, a estrutura de capital e a política de dividendos (ROSS; WESTERFIELD; JAFFE, 2002; GITMAN, 2010).

Ross, Westerfield e Jaffe (2002) abordam tais assuntos agrupando-os em uma área que denominam como valor e orçamento de capital e englo- 
ba: mercados financeiros, avaliação de obrigações e ações, orçamento de capital e a composição da estrutura de capital, associando-a à política de dividendos.

A área administração financeira a curto prazo, também chamada de decisões financeiras de curto prazo e de planejamento financeiro, segundo Ross, Westerfield e Jaffe (2002), Assaf Neto (2014) e Gitman (2010), envolve os conteúdos relacionados à gestão do capital de giro, ao fluxo de caixa e à administração de caixa, à gestão de crédito e às contas a receber, às contas a pagar e à administração financeira dos estoques.

$\mathrm{Na}$ área tópicos especiais, são agrupados os conteúdos que comumente não se enquadram nas demais áreas mais convencionais, principalmente, no que tange aos temas emergentes na área como finanças comportamentais e microfinanças. Gitman (2010), por exemplo, aborda nela os títulos híbridos e derivativos; fusões e aquisições alavancadas, alienações e falência de empresas e administração financeira internacional.

Todos esses aspectos permitem perceber a amplitude e complexidade da área financeira, cuja importância para os indivíduos e as organizações tende a despertar inúmeras necessidades e interesses por um maior conhecimento de suas especificidades, de sua aplicação e de seu desenvolvimento, objetos naturais da pesquisa científica.

\section{BIBLIOMETRIA}

A bibliometria é uma área de estudos da ciência da informação que tem por objetivo analisar a atividade científica pelo estudo quantitativo das publicações. De acordo com Macias-Chapula (1998), a bibliometria estuda os aspectos quantitativos da produção, da disseminação e do uso da informação registrada. Ela desenvolve padrões e modelos matemáticos para medir esses processos, usando seus resultados para elaborar previsões e apoiar tomadas de decisões. Barbosa et al. (2008, p 3) reforçam tal compreensão quando afirmam que a bibliometria "permite um processo descritivo da comunicação escrita apresentada em livros, artigos de anais e periódicos, monografias, dissertações, teses, entre outros", de forma eficaz para a gestão da informação. 
Surgida no início do século XX para a contagem de documentos, palavras de documentos, termos, citações e referências bibliográficas, a bibliometria foi, ao longo do tempo, aperfeiçoando-se e ampliando a sua atuação, conforme explica Araújo (2006, p. 12-13):

\begin{abstract}
Inicialmente voltada para a medida de livros (quantidade de edições e exemplares, quantidade de palavras contidas nos livros, espaço ocupado pelos livros nas bibliotecas, estatísticas relativas à indústria do livro), aos poucos, foi se voltando para o estudo de outros formatos de produção bibliográfica, tais como artigos de periódicos e outros tipos de documentos, para depois ocupar-se, também, da produtividade de autores e do estudo de citações.
\end{abstract}

Para Machado, Barbosa e Quintana (2011, p. 58), a bibliometria destaca-se por padronizar procedimentos que facilitam organizar e mensurar os dados obtidos, possibilitando:

Revelar informações sobre a produção científica realizada e sobre os aspectos importantes tratados, agregando assim conhecimento que pode ser explorado tanto pelas novas publicações que almejam tratar sobre tais assuntos, quanto pelas que pretendem tratar sobre assuntos ainda não explorados.

Segundo Guedes e Borschiver (2005), Araújo (2006) e Ribeiro (2015), entre outros, a bibliometria possui alguns princípios empíricos resultantes dos aprimoramentos da disciplina ao longo do tempo que foram sendo denominados como leis. Os mais significativos são a Lei de Bradford, a Lei de Lotka e a Lei de Zipf.

A Lei de Bradford é também conhecida como Lei da Dispersão, trata da produtividade dos periódicos, fazendo a estimativa do grau de relevância das revistas científicas em relação às áreas do conhecimento abordadas por elas. Aborda que os periódicos que produzem o maior número de artigos sobre um assunto tendem a formar um núcleo de maior qualidade sobre a área a ele relacionada. É aplicada para a identificação de quais periódicos são os mais adequados para o envio de artigos relacionados a determinado 
assunto, assim como para o processo de decisão de aquisição e descarte de periódicos por parte de gerenciadores de acervos (ARAÚJO, 2006).

A Lei de Lotka ou Lei do Quadrado Inverso trata da produtividade científica dos autores em dada área do conhecimento, por meio da identificação de uma frequência de publicações. Sua premissa básica é de que "alguns pesquisadores, supostamente de maior prestígio em uma determinada área do conhecimento, produzem muito e muitos pesquisadores, supostamente de menor prestígio, produzem pouco”. É aplicada na avaliação da produtividade de pesquisadores, na identificação dos centros de pesquisa mais desenvolvidos em dada área de assunto e no reconhecimento da "solidez" de uma área científica (GUEDES; BORSCHIVER, 2005, p. 3).

Já a Lei de Zipf ou do Mínimo Esforço trata da frequência da ocorrência de palavras nos textos, gerando listagens dos termos mais e menos usados. Possibilita identificar os principais assuntos tratados nos textos, assim como o estilo dos autores, com isso, visando contribuir para a indexação automática, em parte ou no todo, de textos científicos e tecnológicos. "É utilizada como ferramenta estatística, em diferentes áreas do conhecimento, tais como linguística, urbanismo, medicina, economia, engenharia, entre outras." (GUEDES; BORSCHIVER, 2005, p. 10).

O reconhecimento da importância da bibliometria e de sua capacidade para se inferir a evolução da produção científica de qualquer tema e origem, assim, fornecendo dados para o seu aperfeiçoamento e direcionamento, levou ao desenvolvimento de inúmeros trabalhos nas mais diversas áreas do conhecimento, inclusive, na financeira.

No universo das publicações de âmbito nacional da área de administração, observam-se alguns artigos relevantes para o tema aqui proposto, como o trabalho realizado por Oliveira (2002), que fez uma análise das publicações de cinco periódicos brasileiros de contabilidade entre 1990 a 1999; assim como o de Leal, Oliveira e Soluri (2003), que figura entre os primeiros a quantificar a produção científica em finanças no Brasil ao analisar artigos publicados entre 1974 e 2001, em cinco conceituadas revistas científicas e nos Anais do Encontro Nacional da Associação Nacional de Pós-Graduação e Pesquisa em Administração; também, Silva, Oliveira e Ribeiro Filho 
(2005), que analisaram as publicações da revista Contabilidade $\&$ Finanças - USP no período de 2001 à 2004; bem como Leite Filho e Siqueira (2007), que analisaram as publicações do mesmo periódico referentes ao período de 1999 a 2006; e Gomes et al. (2007), que fizeram um estudo sobre a produção científica em contabilidade dos artigos publicados nos congressos da USP entre 2004 a 2006.

Individuaram-se, ainda, os trabalhos feitos por Barbosa et al. (2008), que realizaram uma análise bibliométrica da Revista Brasileira de Contabilidade no período de 2003 a 2006; Leal, Almeida e Bortolon (2013), que fizeram uma análise da produção científica brasileira em finanças no período 2000-2010, publicados em 11 periódicos científicos brasileiros; Amaral et al. (2014), que analisaram o perfil dos autores de artigos sobre o mercado financeiro nos congressos USP de Controladoria e Contabilidade e nos congressos da Associação Nacional de Programas de Pós-graduação em Ciências Contábeis; e Herling et al. (2015), que fizeram um mapeamento das publicações em finanças nos periódicos Qualis A entre 2010 e 2012.

Um aspecto comum entre os autores citados é o destaque para a importância de acompanhar e avaliar periodicamente o desenvolvimento da pesquisa científica em finanças no Brasil, observando, também, nesse processo, questões relacionadas aos aspectos metodológicos, temáticos, referenciais, entre outros, das publicações que são realizadas nos periódicos científicos relacionadas à divulgação de tais pesquisas em prol do aprimoramento da qualidade do conteúdo e da forma, por conseguinte, obtendo maior difusão e democratização do conhecimento. 


\section{METODOLOGIA}

Para a realização deste artigo foi executada uma pesquisa descritiva, uma vez que, segundo Duarte e Furtado (2014, p. 26), sendo delineada por objetivos, "havendo um problema de pesquisa científica claramente elaborado" e buscando "descrever as características de determinada população, ou fenômeno [...] em determinado contexto espacial e temporal”, é a que melhor se adaptava ao trabalho proposto.

Quanto aos procedimentos, utilizou-se inicialmente a pesquisa bibliográfica para se obter maior conhecimento sobre finanças e a organização de seus diversos temas de estudo, assim como sobre a bibliometria e sua aplicação para a identificação das características de trabalhos científicos publicados. Na sequência, utilizou-se a análise bibliométrica para a coleta e o tratamento dos dados oriundos dos artigos científicos selecionados. A abordagem para a análise e apresentação dos dados foi quantitativa.

Para a análise bibliométrica foram selecionados como indicadores a quantidade de artigos publicados por ano, os gêneros e as titulações dos autores, a quantidade de autores por artigo (coautorias), a filiação acadêmica e a localização geográfica de tais instituições educacionais, a identificação dos autores que mais publicaram artigos na revista, no período analisado e as temáticas da área de finanças mais abordadas.

Foram analisados os artigos oriundos da demanda universal, apresentados na seção "Artigos" da Revista de Administração de Empresas (RAE) da FGV/SP, publicados em seu site na Internet. Portanto, não foram registradas resenhas e indicações bibliográficas, nem os artigos publicados como Fórum e Clássicos, de modo a evitar qualquer viés que comprometesse a interpretação dos dados.

O universo da pesquisa foi composto por 56 edições da revista, lançadas no período de 2006 a 2016, totalizando 253 artigos, sendo destes, 32 relacionados à área de finanças. A amostra correspondeu a todos os artigos relacionados à área de finanças.

Decidiu-se pelo recorte de 10 anos por se considerar um período de tempo satisfatório para se obter informações mais substanciadas so- 
bre as características atuais da produção científica em finanças publicadas pela RAE.

A unidade de análise, ou seja, o elemento da realidade a respeito do qual as variáveis se referem, foi a produção científica em finanças publicada pela revista RAE. Já a unidade de observação, a fonte de informação a respeito da variável, foi o site do periódico para o acesso a todas as edições da revista RAE publicadas no período analisado e a Plataforma Lattes do CNPq para a obtenção de informações relacionadas aos autores.

Acerca das informações relacionadas aos autores, como a titulação e a instituição de origem, utilizou-se como referência a data da submissão.

Após a coleta dos dados nos artigos científicos, estes foram estruturados e categorizados de acordo com os indicadores bibliométricos selecionados, contando com o auxílio do software Microsoft Excel 2010. 


\section{APRESENTAÇÃO E ANÁLISE DOS RESULTADOS}

Utilizando-se da análise bibliométrica, o estudo buscou evidenciar as características das publicações da RAE de modo a obter a realização dos objetivos propostos. No período entre os anos de 2006 a 2016, a RAE publicou 56 edições, distribuídas entre os volumes 46 e 56, sendo quatro edições por ano, de forma trimestral, entre 2006 a 2010; e seis edições por ano, bimestrais, de 2011 em diante.

\section{CARACTERÍSTICAS DOS ARTIGOS}

Ao longo do período analisado, foram publicados na seção "Artigos" 253 estudos, sendo que destes, 32 (12,6\%) eram referentes à área de finanças, conforme apresentado na tabela 1.

Tabela 1 Quantidade de artigos segundo as áreas de estudo da Administração

\begin{tabular}{c|c|c}
\hline Áreas dA Administração & NúMERO DE & $\begin{array}{c}\text { ArTigos } \\
\text { AO TELAÇão }\end{array}$ \\
\hline Organizações & 47 & $18,5 \%$ \\
\hline Marketing & 39 & $15,4 \%$ \\
\hline Ensino e Pesquisa em & 37 & $14,6 \%$ \\
Administração & 32 & $12,6 \%$ \\
\hline Finanças & 24 & $9,4 \%$ \\
\hline Recursos Humanos & 23 & $9,0 \%$ \\
\hline Planejamento Estratégico & 20 & $7,9 \%$ \\
\hline Tecnologia da Informação & 20 & $7,9 \%$ \\
\hline Outras áreas & 11 & $4,35 \%$ \\
\hline Produção e Logística & 253 & $100 \%$ \\
\hline Total & & \\
\hline
\end{tabular}

Fonte: Revistas RAE do período de 2006 a 2016. 
A Tabela 1 permite perceber que no período analisado a área de organizações foi a que mais teve na RAE publicações relacionadas a ela, com $18,5 \%$ do total, seguida pela área de marketing com $15,4 \%$ e do tema pesquisa e ensino em administração com 14,6\%. Finanças foi a quarta área mais publicada.

Quanto à distribuição anual dos artigos de finanças, o Gráfico 1, a seguir, permite observar que a participação de finanças não foi homogênea, com anos sem nenhum artigo publicado e outros com cinco artigos publicados. A média de publicações relacionadas a finanças na revista, no período analisado, foi de 2,9 trabalhos desta área por ano, ou 0,57 por edição.

Gráfico 1 Participação anual dos artigos relacionados a finanças frente ao total publicado entre 2006 e 2016

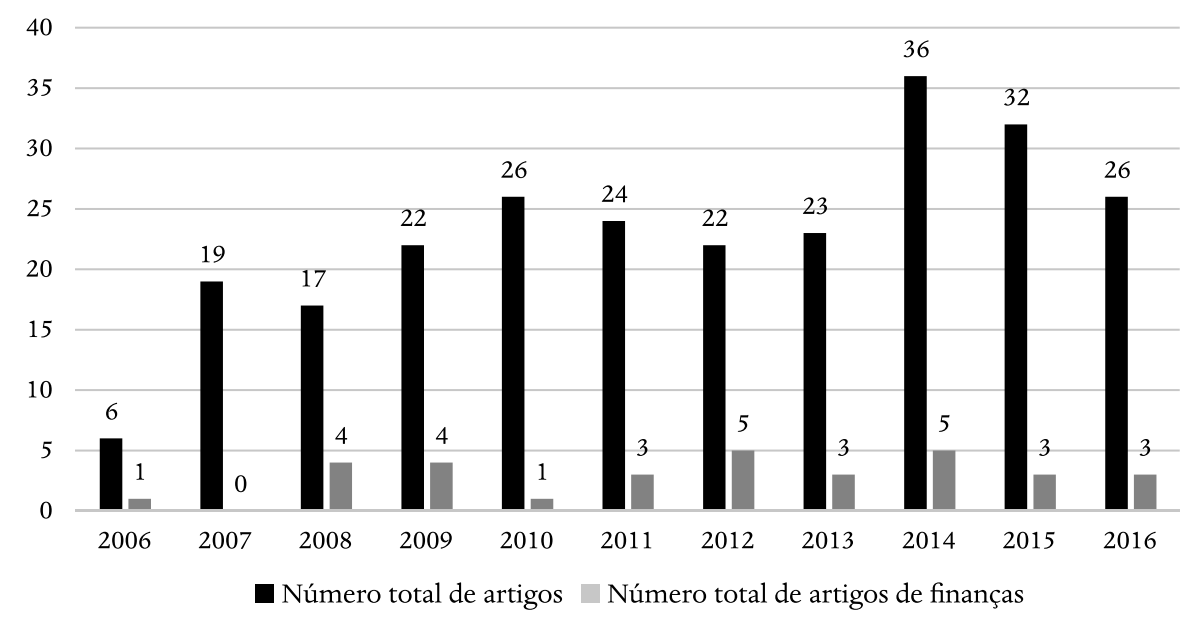

Fonte: Revistas RAE do período de 2006 a 2016.

Percebeu-se que o aumento do número de publicações anuais a partir de 2011, quando a periodicidade da revista passou de trimestral para bimestral, propiciou um aumento de $21,6 \%$ na participação de finanças em relação ao total de trabalhos, visto que sua participação subiu de $11,1 \%$ do total, entre 2006 e 2010, para 13,5\%, entre 2011 e 2016. 
No caso da participação dos trabalhos em finanças por edição da revista, sua média também subiu, indo de 0,5 no período entre 2006 e 2010, para 0,61 artigos por edição após 2011 , um aumento de $22 \%$. Deve-se registrar, também, que, após a mudança de periodicidade, observou-se que em todos os anos foram publicados pelo menos dois trabalhos da área, o que não tinha ocorrido no período anterior.

\section{PERFIL DOS AUTORES}

Os 32 artigos de finanças foram escritos por 73 autores distintos, porém, considerando a repetição de autoria pela publicação de mais de um trabalho, totalizaram-se 83 autores. Nas análises seguintes, foi considerado o número total de autores de modo a representar todos os artigos identificados.

A maioria dos trabalhos publicados relacionados à área de finanças foi escrita por mais de um autor, $93,7 \%$ do total, sendo que quase $50 \%$ dos trabalhos foram confeccionados em dupla, indicando uma preferência dos autores pela produção coletiva, conforme indicado na Tabela 2 .

Tabela 2 Quantidade de autores por artigo de finanças

\begin{tabular}{c|c|c}
$\begin{array}{c}\text { Número DE } \\
\text { AUTORES }\end{array}$ & $\begin{array}{c}\text { QuANTIDADE DE } \\
\text { AUTORES }\end{array}$ & $\begin{array}{c}\text { \% EM RELAĈ̃O } \\
\text { AO TOTAL }\end{array}$ \\
\hline 1 & 2 & $6,2 \%$ \\
\hline 2 & 15 & $46,8 \%$ \\
\hline 3 & 9 & $28,1 \%$ \\
\hline 4 & 6 & $18,7 \%$ \\
\hline Total & 32 & $100 \%$ \\
\hline
\end{tabular}

Fonte: Revistas RAE do período de 2006 a 2016.

Dos 32 artigos, sete tiveram a participação de autores estrangeiros ( $21,8 \%$ do total), sendo que dois foram os únicos trabalhos individuais apontados, publicados, ambos, em 2015. As publicações com três ou quatro 
ROGÉRIO MARTINS FURTADO DE SOUZA, MATHEUS WIVER MOTA ISSN 2358-09I7 BAIA, ISABELA CRISTINA MENDES COSTA, RICARDO SENA

MACHADO, ANA LUIZA BARBOSA MENDES \& MATEUS VIEIRA SOUTO

autores foram mais frequentes em 2008 e 2009, nos demais anos até 2015, elas foram em média uma por ano.

Para um melhor conhecimento das características desses autores, o estudo procurou identificá-los por gênero, titulação e origem, conforme pode-se observar a seguir.

Conforme os autores por gênero, entre os 83 assinados nas publicações, observou-se que a grande maioria era formada por homens, $74,7 \%$ contra 25,3\% de mulheres, sendo que em 2006, 2007 e 2010, entre as publicações relacionadas a finanças, não houve participação de mulheres. Nos demais anos, mulheres participaram da elaboração de pelo menos dois artigos em cada ano. Quatro artigos foram escritos exclusivamente por mulheres e, em treze outros, elas trabalharam em conjunto com colegas do gênero masculino.

Como pode ser observado na Tabela 3, quanto à titulação dos autores, $72,3 \%$ dos trabalhos publicados foram confeccionados por profissionais que tinham doutorado ou $\mathrm{PhD}$, não havendo publicações de especialistas, até em decorrência de serem vetados pelas normas de submissão da revista. Quatro autores eram mestres que estavam cursando doutorado. Entre os autores do gênero masculino, 75,8\% eram doutores ou $\mathrm{PhDs}$, 19,4\% eram mestres e $4,8 \%$ mestrandos. Entre os artigos assinados por mulheres, $61,9 \%$ delas eram doutoras ou $\mathrm{PhDs}$, 33,3\% eram mestras e 4,8\% eram mestrandas.

Tabela 3 Titulação dos autores no momento da submissão de seus artigos

\begin{tabular}{c|c|c} 
TitulaÇÃO & NÚMERO DE AUTORIAS & \% EM RELAÇÃO AO TOTAL \\
\hline Doutor & 50 & $60,2 \%$ \\
\hline PhD & 10 & $12,0 \%$ \\
\hline Mestre & 15 & $18,0 \%$ \\
\hline Doutorando & 4 & $4,8 \%$ \\
\hline Mestrando & 4 & $4,8 \%$ \\
\hline Total & 83 & $100 \%$ \\
\hline
\end{tabular}

Fonte: Revistas RAE do período de 2006 a 2016. 
Torna-se importante registrar que $\mathrm{PhD}$ é uma titulação obtida, principalmente, nos Estados Unidos e que, no Brasil, é considerado equivalente ao título de Doutor concedido pelas universidades nacionais, conforme observado no parecer do Conselho Federal de Educação no 977 / 1965 (CAPES, 2017). A distinção desses títulos na Tabela 3 buscou respeitar a forma como foi declarada pelos autores no corpo do artigo.

Conforme pode ser observado na Tabela 4, com relação à origem dos autores, 74 são brasileiros e nove são estrangeiros, representando 10,8\% do total. Destes, 55,6\% são espanhóis, 44,4\% eram PhDs e 55,6\% doutores. Já entre os autores vinculados a universidades brasileiras, $5,4 \%$ eram mestrandos, $20,27 \%$ deles eram mestres, $5,4 \%$ doutorandos, $60,8 \%$ doutores e $8,1 \% \mathrm{PhDs}$.

Tabela 4 País sede da instituição onde se vincula o autor

\begin{tabular}{c|c|c} 
País & NúMERO DE AUTORES & \% EM RELAÇÃO AO TOTAL \\
Brasil & 74 & $89,2 \%$ \\
\hline Espanha & 5 & $6,0 \%$ \\
\hline Canadá & 1 & $1,2 \%$ \\
\hline Austrália & 1 & $1,2 \%$ \\
\hline China & 1 & $1,2 \%$ \\
\hline Áustria & 1 & $1,2 \%$ \\
\hline Total & 83 & $100 \%$ \\
\hline
\end{tabular}

Fonte: Revistas RAE do período de 2006 a 2016.

Os 83 autores dos 32 artigos estavam vinculados a 29 instituições diferentes, sete estrangeiras e 22 brasileiras. Observou-se que apenas a USP e a FGV/SP respondem por $33,7 \%$ de todas as autorias (vide Tabela 5). Dos artigos, 19 foram escritos interinstituições, dois foram individuais e 11 foram escritos por professores de uma mesma instituição. 
ROGÉRIO MARTINS FURTADO DE SOUZA, MATHEUS WIVER MOTA ISSN 2358-09I7 BAIA, ISABELA CRISTINA MENDES COSTA, RICARDO SENA

MACHADO, ANA LUIZA BARBOSA MENDES \& MATEUS VIEIRA SOUTO

Tabela 5 Instituições a que estavam vinculados os autores quando da submissão dos artigos em finanças

\begin{tabular}{|c|c|c|}
\hline INSTITUIÇÃO & $\begin{array}{l}\text { QuANTI- } \\
\text { DADE DE } \\
\text { ARTIGOS }\end{array}$ & $\begin{array}{c}\% \text { EM } \\
\text { RELAÇÃO AO } \\
\text { TOTAL }\end{array}$ \\
\hline Fundação Getulio Vargas - FGV/SP & 16 & $19,2 \%$ \\
\hline Universidade de São Paulo - USP & 12 & $14,4 \%$ \\
\hline Universidade Presbiteriana Mackenzie - MACKENZIE & 7 & $8,4 \%$ \\
\hline Fucape Business School - FUCAPE & 5 & $6,0 \%$ \\
\hline Fundação Escola de Com. Álvares Penteado - FECAP & 4 & $4,8 \%$ \\
\hline Instituição de ensino superior em São Paulo - INSPER & 3 & $3,6 \%$ \\
\hline Universidade Federal de Juiz de Fora - UFJF & 3 & $3,6 \%$ \\
\hline Universidade Federal da Paraíba - UFPB & 3 & $3,6 \%$ \\
\hline Universidade Federal de Santa Catarina - UFSC & 3 & $3,6 \%$ \\
\hline Universidade Federal de Itajubá - UNIFEI & 3 & $3,6 \%$ \\
\hline Pontifícia Universidade Católica - PUC-SP & 2 & $2,4 \%$ \\
\hline Universidade Federal do Ceará - UFC & 2 & $2,4 \%$ \\
\hline Universidad Politécnica de Valência & 2 & $2,4 \%$ \\
\hline Universidad Pública de Navarra & 2 & $2,4 \%$ \\
\hline Banco Central do Brasil - Bacen & 2 & $2,4 \%$ \\
\hline Centro Universitário - FEI & 1 & $1,2 \%$ \\
\hline Changzhou University & 1 & $1,2 \%$ \\
\hline Fundação Armando Alvares Penteado - FAAP & 1 & $1,2 \%$ \\
\hline Fundação de Economia e Estatística - FEE & 1 & $1,2 \%$ \\
\hline Faculdade Novos Horizontes - FNH & 1 & $1,2 \%$ \\
\hline HEC Montreal & 1 & $1,2 \%$ \\
\hline Faculdade de Econ. e Finanças Ibmec - IBMEC/RJ & 1 & $1,2 \%$ \\
\hline Universidade Federal de Minas Gerais - UFMG & 1 & $1,2 \%$ \\
\hline Universidade Federal do Paraná - UFPR & 1 & $1,2 \%$ \\
\hline Universidade de Brasília - UNB & 1 & $1,2 \%$ \\
\hline Universidad de Salamanca & 1 & $1,2 \%$ \\
\hline Universitat Wien & 1 & $1,2 \%$ \\
\hline University of Adelaide & 1 & $1,2 \%$ \\
\hline Universidade Positivo - UP & 1 & $1,2 \%$ \\
\hline Total & 83 & $100 \%$ \\
\hline
\end{tabular}

Fonte: Revistas RAE do período de 2006 a 2016 
O presente trabalho não permite identificar as razões de existir maior volume de publicações de autores da FGV/SP e da USP, considerando que várias outras instituições de relevância nacional poderiam ter melhor participação em tal distribuição. Pode-se apenas supor que tal aspecto tenha relação com a ocorrência de maior similaridade entre a abordagem acadêmica adotada pelos professores de tais instituições e a linha editorial seguida pela revista.

Outro dado a apontar é que $56,8 \%$ dos autores vinculados às instituições brasileiras trabalhavam em instituições privadas quando da submissão dos artigos e $43,2 \%$ em instituições públicas. Destes, $81,1 \%$ estavam na região Sudeste, $8,1 \%$ na região Sul, $6,8 \%$ na região Nordeste e $4,1 \%$ na região Centro-Oeste.

De acordo com a Lei de Lotka, é de se esperar que alguns autores sejam mais produtivos que outros e, por consequência, acabem publicando com mais frequência, mesmo em periódicos de alta demanda e exigência (GUEDES; BORSCHIVER, 2005). Assim, analisando os dados dos autores mais produtivos da área de finanças da RAE, no período analisado, pôde-se perceber que oito autores participaram da publicação de mais de um artigo, correspondendo a $34,4 \%$ dos 32 artigos e $21,6 \%$ do total de autorias. Três deles publicaram juntos os mesmos artigos. Estes são todos do gênero masculino e metade deles pertence à própria FGV, instituição mantenedora da revista. Excetuando-se os autores citados na Tabela 6, todos os demais participaram da publicação de apenas um artigo no período.

Segundo a análise das titulações dos autores mais produtivos, todos eles são doutores e apenas um era mestre quando da submissão de seu primeiro trabalho.

Quanto aos temas da área de finanças explorados pelos autores no desenvolvimento de seus trabalhos, nos 32 artigos foram abordados 18 temas diferentes. Tal variedade de temas evidencia a amplitude e a profundidade da área financeira e as suas inúmeras possibilidades de estudos. Destaca-se, entretanto, a predominância de temas voltados ao mercado financeiro e à gestão de grandes negócios, notadamente mais valorizados do que aqueles que tratam da realidade dos micro e pequenos negócios e que refletem o foco observado nas obras dos principais autores clássicos adotados no Brasil, nacionais e estrangeiros. 
Tabela 6 Autores mais produtivos em finanças no período analisado

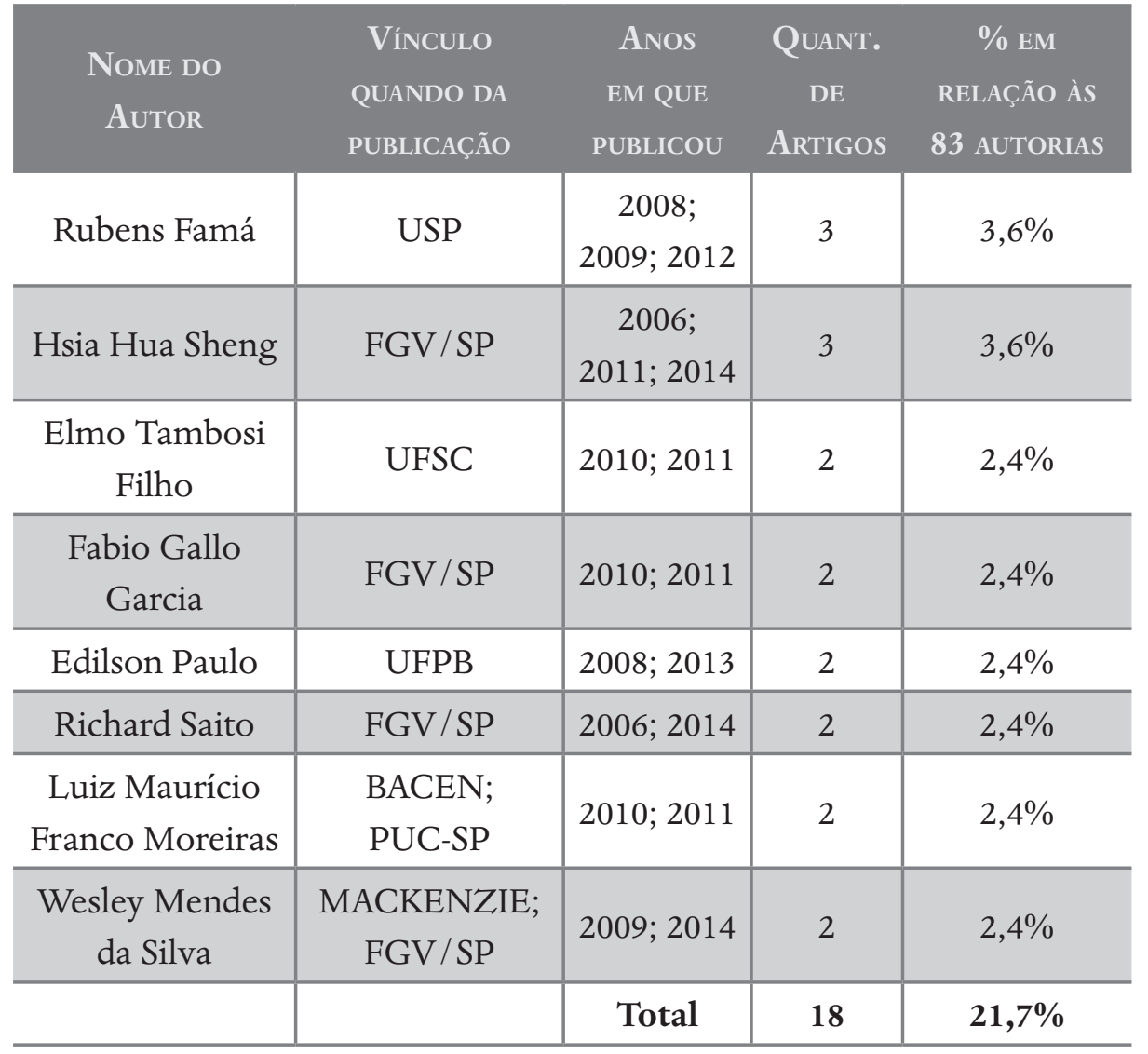

Fonte: Revistas RAE do período de 2006 a 2016

Os temas mais abordados foram "governança corporativa" e "mercado de capitais", cada um dos dois foi base para cinco artigos, em torno de $16 \%$ do total para cada um, conforme apresentado na Tabela 7. 
Tabela 7 Temas de finanças mais publicados no período analisado

\begin{tabular}{|c|c|c|c|}
\hline TEMAS DE FINANÇAS & $\begin{array}{c}\text { ANOS EM QUE } \\
\text { FORAM PUBLICADOS }\end{array}$ & $\begin{array}{l}\text { Quant. De } \\
\text { Artigos }\end{array}$ & $\begin{array}{c}\text { \% EM RELAÇão } \\
\text { AO TOTAL }\end{array}$ \\
\hline $\begin{array}{l}\text { Governança } \\
\text { Corporativa }\end{array}$ & $\begin{array}{c}2008 ; 2009 ; 2013 ; \\
2015 ; 2016\end{array}$ & 5 & $15,6 \%$ \\
\hline Mercado de Capitais & $\begin{array}{c}2009 ; 2012(2) ; \\
2013 ; 2014\end{array}$ & 5 & $15,6 \%$ \\
\hline Contabilidade & $2008 ; 2015$ & 2 & $6,2 \%$ \\
\hline Fusões e Aquisições & $2009 ; 2014$ & 2 & $6,2 \%$ \\
\hline Política de Dividendos & $2012(2)$ & 2 & $6,2 \%$ \\
\hline $\begin{array}{l}\text { Análise das Demonstra- } \\
\text { ções Financeiras }\end{array}$ & $2011(2)$ & 2 & $6,2 \%$ \\
\hline Custos & $2009 ; 2011$ & 2 & $6,2 \%$ \\
\hline Risco e Retorno & $2010 ; 2014$ & 2 & $6,2 \%$ \\
\hline Educação Financeira & 2016 & 1 & $3,1 \%$ \\
\hline Avaliação de Empresas & 2016 & 1 & $3,1 \%$ \\
\hline $\begin{array}{l}\text { Planejamento } \\
\text { Financeiro }\end{array}$ & 2015 & 1 & $3,1 \%$ \\
\hline Estrutura de Capital & 2014 & 1 & $3,1 \%$ \\
\hline Orçamento de Capital & 2014 & 1 & $3,1 \%$ \\
\hline $\begin{array}{l}\text { Gestão de Contas a } \\
\text { Receber }\end{array}$ & 2013 & 1 & $3,1 \%$ \\
\hline Gestão baseada no Valor & 2012 & 1 & $3,1 \%$ \\
\hline $\begin{array}{l}\text { Finanças } \\
\text { Comportamentais }\end{array}$ & 2008 & 1 & $3,1 \%$ \\
\hline $\begin{array}{l}\text { Modelos de Precificação } \\
\text { de Ativos }\end{array}$ & 2008 & 1 & $3,1 \%$ \\
\hline \multirow[t]{2}{*}{$\begin{array}{l}\text { Taxa de juros e avaliação } \\
\text { de obrigações }\end{array}$} & 2006 & 1 & $3,1 \%$ \\
\hline & Total & 32 & $100 \%$ \\
\hline
\end{tabular}

Fonte: Revistas RAE do período de 2006 a 2016. 
Conforme os temas apresentados na Tabela 7 , à luz das classificações citadas no referencial teórico, adotadas pelos autores clássicos e pela ANPAD, pode-se confirmar a preferência por temas relacionados à gestão de grandes negócios. Utilizando, por exemplo, a classificação adotada pela ANPAD, percebe-se que finanças corporativas seria a área mais utilizada com 34,4\%; governança corporativa e mercados e instituições financeiras ficariam igualadas em segundo com 15,6\%; investimento e apreçamento de ativos viria na sequência com $9,4 \%$ e, por último, ficaria finanças comportamentais com 3,1\%. Não foram inclusos nesta classificação os temas relacionados com contabilidade, custos e educação financeira por, a princípio, não se identificarem com alguma das áreas citadas.

Observa-se que os temas contabilidade e custos, conquanto pertencentes à área de finanças, não estão presentes nas classificações por provavelmente serem estas mais voltadas à administração financeira.

Outro aspecto interessante a ser analisado é a evolução dos temas no decurso do tempo e o perfil de sua autoria. O tema governança corporativa foi abordado pela primeira vez em 2008 e esteve presente em quatro dos oito anos seguintes. Os artigos foram confeccionados por equipes de dois a quatro autores, principalmente, vinculados à USP, com 42,9\% do total, e às universidades estrangeiras, com $21,4 \%$. Já os artigos relacionados ao tema mercado de capitais foram publicados entre 2009 e 2014. Foram, mormente, confeccionados por equipes de três autores, de diversas universidades, com destaque para a FECAP e a FUCAPE, com $25 \%$ do total cada uma. Em ambos os casos, cerca de $80 \%$ dos autores são do gênero masculino e pelo menos $70 \%$ deles já tinham doutorado quando da submissão dos seus artigos.

Quanto aos demais temas, esses foram publicados apenas uma ou duas vezes, por consequência da grande diversificação, assim, não se permitindo uma análise mais apurada de sua evolução. Considerando o agrupamento destes por área, pôde-se perceber que os temas relacionados a finanças corporativas, a área mais utilizada, foram publicados entre 2009 e 2015, sendo confeccionados, particularmente, por duplas de autores, pertencentes a diversas universidades diferentes, com mais destaque para a FGV com 
ANÁLISE BIBLIOMÉTRICA DOS ARTIGOS CIENTÍFICOS EM FINANÇAS PUBLICADOS NA REVISTA DE ADMINISTRAÇÃO DE EMPRESAS (RAE) DA FGV/SP, NO PERÍODO DE 2006 A 2016

$32 \%$ do total, e para autores vinculados a universidades estrangeiras com $16 \%$. Nesta área foi expressiva a participação de autores do gênero feminino com $40 \%$ do total e pelo menos $75 \%$ deles já tinham doutorado. 
Os dados analisados possibilitaram compreender com maior detalhe as características dos artigos de finanças publicados pela RAE, no período de 2006 a 2016, identificando que a maioria dos artigos foi produzida por profissionais brasileiros com doutorado, do gênero masculino e vinculados a instituições estabelecidas na região Sudeste, principalmente, da FGV e da USP. Individuou-se grande variedade entre os temas de finanças abordados, sendo que governança corporativa e mercado de capitais foram os mais publicados.

A Revista de Administração de Empresas (RAE) da Fundação Getulio Vargas de São Paulo (FGV/SP), é um dos periódicos de administração mais conceituados do Brasil. Sua importância reflete-se nos artigos por ela publicados, o que reforça a significância do trabalho realizado e seus resultados.

A análise bibliométrica das publicações da RAE mostrou-se eficaz para a realização dos objetivos propostos para o trabalho, correspondendo ao que foi exposto na literatura estudada. No mesmo sentido, também, fez-se a bibliografia estudada de finanças que possibilitou maior conhecimento de seus temas de estudo e sua organização.

A participação da área de finanças entre o total de trabalhos publicados mostrou-se significativa, assim como nesta, houve predominância de temas voltados ao mercado financeiro e à gestão de grandes empresas. Observou-se a preferência pela publicação coletiva, a alta qualificação da titulação dos autores, a existência de uma pequena participação de autores estrangeiros, mas, também, a desigualdade geográfica na distribuição das publicações entre as instituições, com total predomínio da região Sudeste e notadamente da cidade de São Paulo.

A análise da evolução ao longo do tempo dos temas e do perfil de sua autoria permitiu evidenciar que os temas mais publicados e os temas relacionados a finanças corporativas, a área mais utilizada segundo a classificação adotada pela ANPAD, compartilham de características muito similares como a preferência pelo trabalho coletivo e a predominância de autores do gênero masculino, com doutorado, oriundos de diversas universidades, 
mas com forte participação da FGV, e terem sido publicados ao longo de quase todo o período analisado.

Como sugestão para pesquisas futuras, recomenda-se a ampliação deste estudo para englobar os demais trabalhos publicados na RAE no período, mormente, os oriundos dos fóruns temáticos, que, apesar de serem de uma demanda direcionada, podem propiciar novas informações ou mesmo outro enfoque, desse modo, agregando valor aos conhecimentos aqui adquiridos.

Por fim, cabe ressaltar a importância deste trabalho para os pesquisadores, estudantes, professores e profissionais brasileiros que atuam em finanças, pois propiciou conhecimento sobre a atual produção científica na área, além de ser um norteador para o desenvolvimento de novos estudos. 
ROGÉRIO MARTINS FURTADO DE SOUZA, MATHEUS WIVER MOTA ISSN 2358-09I7

BAIA, ISABELA CRISTINA MENDES COSTA, RICARDO SENA

MACHADO, ANA LUIZA BARBOSA MENDES \& MATEUS VIEIRA SOUTO

\section{REFERÊNCIAS}

AMARAL, M. R. et al. Perfil dos Autores na Produção Científica em Mercado Financeiro de Crédito e de Capitais nos Congressos USP de Controladoria e Contabilidade e Congresso ANPCONT. Revista de Evidenciação Contábil \& Finanças, v. 2, n. 2, p. 55-68, 2014.

ANPAD - Associação Nacional de Pós-Graduação e Pesquisa em Administração. Divisões Acadêmicas / Comitês Científicos / Temas de Interesse - FIN - Finanças. Disponível em: < http:/ / www.anpad.org.br/ anpad/sobre_div_academicas.php >. Acesso em: 16 mar. 2017.

ARAÚJO, C. A. Bibliometria: evolução história e questões atuais. Em Questão, Porto Alegre: UFRGS, v. 12, n. 1, 2006.

ASSAF NETO, A. Curso de Administração Financeira. 3.ed. São Paulo: Atlas, 2014.

BARBOSA, E. T. et al. Uma análise bibliométrica da Revista Brasileira de Contabilidade no período de 2003 a 2006. In: CONGRESSO USP DE CONTROLADORIA E CONTABILIDADE, 8, 2008, São Paulo. Anais... São Paulo, USP, 2008.

CAPES - Coordenação de Aperfeiçoamento de Pessoal de Nível Superior. Definição dos Cursos de Pós-Graduação - Parecer 977 / 65, C.E.Su, aprov. em 03-12-1965.

DUARTE, S. V.; FURTADO, M. S. V. Trabalho de Conclusão de Curso (TCC) em Ciências Sociais Aplicadas. São Paulo: Saraiva, 2014.

GITMAN, L. J. Princípios de Administração Financeira. 12.ed. São Paulo: Person, 2010.

GOMES, R. B. et al. Um estudo sobre a produção acadêmica em contabilidade: uma abordagem nos Congressos USP de Iniciação Científica em Contabilidade. In: CONGRESSO USP DE INICIAÇÃO CIENTÍFICA EM CONTABILIDADE, 4, 2007, São Paulo. Anais... São Paulo: USP, 2007.

GUEDES, V. L. S. A bibliometria e a gestão da informação e do conhecimento científico e tecnológico: uma revisão da literatura. Revista do instituto de Ciência da Informação da UFBA, v. 6, n. 2, 2012.

GUEDES, V. L. S.; BORSCHIVER, S. Bibliometria: uma ferramenta estatística para a gestão da informação e do conhecimento, em sistemas de informação, de comunicação e de avaliação científica e tecnológica. In: CINFORM - ENCONTRO NACIONAL DE CIÊNCIAS DA INFORMAÇÃO, 6., 2005, p. 1-18, Salvador. Anais... Salvador: UFBA, 2005.

HELFERT, E. A. Técnicas de Análise Financeira. 9. ed. Porto Alegre: Bookman, 2000.

HERLING, L. H. D. et al. Produção científica em finanças: mapeamento das publicações em periódicos Qualis A no Brasil. Revista de Ciências da Administração, v. 17, n. 41, p. 51-64, 2015.

LEAL, R. P. C.; ALMEIDA, V. S.; BORTOLON, P. M. A produção científica brasileira em finanças no período 2000-2010. Revista de Administração de Empresas, v. 53, n. 1, 2013. 
LEAL, R. P. C.; OLIVEIRA, J.; SOLURI, A. F. Perfil da pesquisa em finanças no Brasil.

Revista de Administração de Empresas, v. 43, n. 1, 2003.

LEITE FILHO, G. A.; SIQUEIRA, R. L. Revista Contabilidade \&Finanças USP: uma análise bibliométrica de 1999 a 2006. Revista de Informação Contábil, v. 1, n. 2, 2007.

MACHADO, D. G.; BARBOSA, D. S.; QUINTANA, A. C. Análise da Produção Científica sobre os Fluxos de Caixa e a Demonstração dos Fluxos de Caixa: um estudo da Revista de Contabilidade e Finanças da Universidade de São Paulo, no período de 1989 a 2009. Revista Enfoque: Reflexão Contábil, v. 30, n. 2, p. 52-66, 2011.

MACIAS-CHAPULA, C. A. O papel da infometria e da cienciometria e sua perspectiva nacional e internacional. Ciência da Informação, Brasília: IBICT, v. 27, n. 2, p. 134-140, 1998.

OLIVEIRA, M. C. Análise dos periódicos Brasileiros de contabilidade. Revista Contabilidade $\&$ Finanças, v. 13, n. 29, p. 68-86, 2002.

PLATAFORMA LATTES. Busca de Currículos Lattes. Disponível em: <http:/ / buscacv. cnpq.br/buscacv/\#/>. Acesso em: 03 fev. 2017.

REVISTA de Administração de Empresas. RAE Publicações. Disponível em: < http:/ / rae.fgv.br>. Acesso em: 03 fev. 2017.

RIBEIRO, H. C. M. Quinze anos de estudo da revista de administração contemporânea sob a ótica da bibliometria e da rede social. Revista Perspectivas em Gestão \& Conhecimento, v. 5, Número Especial, p. 86-108, 2015.

ROSS, S. A. Administração Financeira. 2.ed. São Paulo: Atlas, 2002.

SILVA, A. C. B.; OLIVEIRA, E. C.; RIBEIRO FILHO, J. F. Revista contabilidade e finanças USP: uma comparação entre os períodos 1989/2001 e 2001/2004. Revista Contabilidade e Finanças - USP, v. 16, n. 39, 2005. 


\section{DADOS DOS AUTORES}

\section{ROGÉRIO MARTINS FURTADO DE SOUZA^ rogerio.furtado@unimontes.br}

\section{Mestre em Administração pela UFMG}

Instituição de vinculação: Universidade Estadual de Montes Claros

Montes Claros/MG - Brasil

Áreas de interesse em pesquisa: Administração, Administração Financeira, Mercado de Trabalho, Emprego e Renda.

* UNIMONTES - Departamento de Ciências da Administração Avenida Dr. Ruy Braga, S/NPrédio 1, sala 304 Vila Mauriceia Montes Claros/MG 39401-089

\section{MATHEUS WIVER MOTA BAIA matheuswiver@hotmail.com}

\section{Bacharel em Administração pela UNIMONTES}

Instituição de vinculação: Universidade Estadual de Montes Claros

Montes Claros/MG - Brasil

Áreas de interesse em pesquisa: Administração e Administração Financeira.

\section{ISABELA CRISTINA MENDES COSTA isabelahvs@hotmail.com}

\section{Bacharel em Administração pela UNIMONTES}

Instituição de vinculação: Universidade Estadual de Montes Claros

Montes Claros/MG - Brasil

Áreas de interesse em pesquisa: Administração e Administração Financeira.

\section{RICARDO SENA MACHADO ricardo.senamachado@hotmail.com}

\section{Bacharel em Administração pela UNIMONTES}

Instituição de vinculação: Universidade Estadual de Montes Claros

Montes Claros/MG - Brasil

Áreas de interesse em pesquisa: Administração e Administração Financeira.

\section{ANA LUIZA BARBOSA MENDES ana.luiza@gammix.com.br}

\section{Bacharel em Administração pela UNIMONTES}

Instituição de vinculação: Universidade Estadual de Montes Claros

Montes Claros/MG - Brasil

Áreas de interesse em pesquisa: Administração e Administração Financeira. 
ANÁLISE BIBLIOMÉTRICA DOS ARTIGOS CIENTÍFICOS EM FINANÇAS PUBLICADOS NA REVISTA DE ADMINISTRAÇÃO DE EMPRESAS (RAE) DA FGV/SP, NO PERÍODO DE

\section{MATEUS VIEIRA SOUTO mateussoutomoc@yahoo.com.br}

\section{Bacharel em Administração pela UNIMONTES}

Instituição de vinculação: Universidade Estadual de Montes Claros

Montes Claros/MG - Brasil

Áreas de interesse em pesquisa: Administração e Administração Financeira. 